Hughes, S., Makara, K. and Stacey, D. (2020) Learning progression in the humanities: identifying tensions in articulating progression in humanities in Wales. Curriculum Journal, 31(2), pp. 276-289.

There may be differences between this version and the published version. You are advised to consult the publisher's version if you wish to cite from it.

This is the peer reviewed version of the following article:

Hughes, S., Makara, K. and Stacey, D. (2020) Learning progression in the humanities: identifying tensions in articulating progression in humanities in Wales. Curriculum Journal, 31(2), pp. 276-289, which has been published in final form at http://dx.doi.org/10.1002/curj.28

This article may be used for non-commercial purposes in accordance with Wiley Terms and Conditions for Self-Archiving.

http://eprints.gla.ac.uk/208213/

Deposited on: 3 February 2020 


\title{
Learning Progression in the Humanities: Identifying tensions in articulating progression in Humanities in Wales.
}

\author{
Dr Sioned Hughes* Dr Kara Makara ** Dave Stacey* \\ *Yr Athrofa: Institute of Education, University of Wales Trinity Saint David, Wales \\ **School of Education, University of Glasgow, Glasgow, Scotland.
}

External Funding: This research was part-funded by the Welsh Government

Disclosure Statement: No financial interest or potential conflict of interest have arisen from the direct application of our research.

\section{Biographical Note:}

Sioned Hughes is a Senior Lecturer in Initial Teacher Education at Yr Athrofa: Institute of Education, at the University of Wales Trinity Saint David. Her background is in primary and initial teacher education, and she has previously worked as a primary school teacher. Her main research interests include humanities education, local history and assessment.

Kara A. Makara, CPsychol is a Lecturer in the School of Education, University of Glasgow. She has a PhD in Educational Psychology. Her research focuses on how social interactions in educational settings influence motivation and learning. Her research interests include academic and social goals, peer relationships, assessment, and academic help-seeking.

Dave Stacey is a Senior Lecturer in Initial Teacher Education at Yr Athrofa, University of Wales Trinity Saint David. Before joining the institute, he taught History in a secondary school in South Wales. His research interests include curriculum development and assessment reform.

Data Availability Statement: No data set was associated with the paper.

Data Deposition: No data has been made available or deposited in a recognized data repository prior to or at the time of submission.

Geolocation Information: The research work was conducted in Wales, United Kingdom.

Acknowledgement: We would like to thank Dylan E. Jones, Louise Hayward \& Jane Waters as professional leaders on the CAMAU project, Jane Waters for being a critical friend on the last draft, and the Welsh Government and the Pioneers for all of their support. 


\section{Learning Progression in the Humanities: Identifying tensions in articulating progression in Humanities in Wales}

The paper explores tensions in the articulation of progression in learning across the Humanities disciplines. Informed by our review of research in the Humanities disciplines, international curricula on progression in these areas, and reflections from professional activity within the newly defined Humanities 'Area of Learning and Experience' (AoLE) in the new Welsh curriculum, this paper describes how learning progression in Humanities has been conceptualised within the new curriculum and then delineates and critically reviews four challenges that emerged when identifying and describing progression in learning in the new Humanities curriculum. Tensions include the relationship between disciplines; the balance between knowledge, skills and values; the differences between underlying models of progression in Humanities; and balancing the complexity of learning with practical considerations for a national curriculum. Underpinned by the Integrity Model of Change, this paper makes a contribution, through providing new insights on broad aspects of learning progression in Humanities and highlighting potential benefits and challenges of taking particular decisions within each of these four tensions. Implications for curriculum planning and future research are offered, including the fundamental role of professional learning in curriculum development and enactment.

Keywords: humanities; social studies; conceptualisation of progression in learning; learning progression; interdisciplinary; curriculum planning; 


\section{Introduction}

This is a conceptual paper which identifies and reviews tensions which emerged during the early stages of articulating a learning progression framework for the newly defined Humanities 'Area of Learning and Experience' (AoLE) within the new Welsh curriculum. Firstly, we describe the context of the new Curriculum for Wales and the role of learning progression. Secondly, we describe our CAMAU project and the theoretical framework which underpinned this phase of our work. Thirdly, we critically review four tensions that were identified when describing progression in learning in the Humanities: the relationship between disciplines; the balance between knowledge, skills and values; different models underlying progression in Humanities; and ensuring the complexity of learning is capturing the complexity of learning within the practical parameters of a national curriculum. Through this paper we aim to inform current reform efforts internationally and contribute to a better understanding of the conceptual nature of learning progression within Humanities disciplines.

\section{Curriculum Reform in Wales}

Wales is currently undertaking significant curricula reform following a systematic review of the country's education system. Since the devolution of education to the Welsh Government in 1999, several reforms have been undertaken, including an increased emphasis on skills across the curriculum (Welsh Government, 2008). However, disappointing PISA results (OECD, 2010), concerns about the relative performance of children and young people in Wales in national qualifications (HMCI Wales, 2012), and evaluations by Estyn (the education training inspectorate for Wales) (2014), suggested a fall in educational standards. Concerns were raised about transition between education stages, too much emphasis on summative assessment, and a culture 
diminishing the professional contribution of the teaching workforce (Estyn, 2014; OECD, 2014; Donaldson, 2015). Therefore, a review of the national curriculum and assessment arrangements in Wales was undertaken and the recommendations made in the report, Successful Futures (Donaldson, 2015) on the design of a new, purpose led curriculum, were accepted in full by the Welsh Government. Rather than a framework of subjects to be taught over particular years of primary and secondary education, the focus is on ensuring children and young people develop as: 'ambitious, capable learners, enterprising, creative contributors, ethical, informed citizens of Wales and the world; and healthy, confident individuals, ready to lead fulfilling lives as valued members of society' (Donaldson, 2015, p. 29). To achieve these four purposes, it was recommended that the curriculum be structured around six broad Areas of Learning and Experiences (AoLEs) which draw together what currently exists as distinct academic and vocational subjects. Humanities is one of these AoLEs and includes the study of History, Geography, Religious Education (RE), Business and Social Studies.

\section{Learning Progression in the New Curriculum}

In contrast to the current system, which has different assessment systems at different points in the curriculum, the recommendations from Donaldson (2015), adopted by Welsh Government, specify that the new curriculum should be organised as a continuum of learning from ages 3 to 16 . Progression is to be organised within each AoLE and described at five 'progression steps', not as standards or levels (as used in the previous curriculum) which define universal expectations, but reference points which provide a 'road map' for each individual child within a system which 'conceptualises learning as akin to an expedition' (Donaldson, 2015, p. 114). When designing the new curriculum for Wales, it was recommended that better alignment is needed between policy, research and practice as well as adherence to the principle of 'subsidiarity', 
which is defined as "commanding the confidence of all, while encouraging appropriate ownership and decision making by those closest to the teaching and learning process" (Donaldson, 2015, p.14). In contrast to more top-down approaches (Kelly, 2009) and many international models, the aim of the approach in Wales is to place teachers at the heart of developing the Curriculum for Wales. Therefore, a 'Pioneer' school model was adopted, where Pioneer schools hold collective responsibility for developing the curriculum and the subsequent dissemination of their approaches (Welsh Government, 2015). Professionals from these schools were further supported by Welsh government consortia leads, disciplinary experts and academics input from various stakeholders, and a range of consultants.

Wales' approach to incorporating learning progression within curriculum design is innovative in bringing together multiple forms of evidence, for example, research on learning progression, teacher and pupil understandings of progression, and insights from other national frameworks, in order to create bespoke progression frameworks for each AoLE tailored to the needs of young people in Wales (Hayward, et al., 2018).

Successful Futures is an example of a new wave of curriculum emerging in many countries around the world (OECD, 2014) These curricula exhibit common-features, including replacement of subject specification by interdisciplinary areas of learning, the specification of learning outcomes and key competences, learner-centeredness and the central role of teachers as curriculum developers (Priestley \& Biesta, 2013; Priestley \& Drew, 2016).

\section{Conceptualisation of Learning Progression}

Learning progressions are descriptions of the pathways along which students move towards more sophisticated understandings and skills within areas of learning. Progression steps, the building blocks of students' learning trajectories, can be 
conceptualised in many ways (Heritage, 2008), such as moving from novice to expert, learning a series of different concepts and/or skills, or increased independence in enacting concepts and skills. Progression could refer to the development of understandings, skills and/or capacities within one lesson, one unit, across a year, or across schooling, or across lifelong learning. An effective understanding of progression is a vital element in achieving the potential offered by formative assessment, or Assessment for Learning. Since Black and Wiliam's (1998) seminal review, countries around the world have sought to realise the potential of Assessment for Learning, yet its enactment has been patchy (Hayward \& Spencer, 2010; Marshall \& Drummond, 2006) and problems around the articulation of progression has been part of the problem (Hayward, et al., 2018). Assessment for formative purposes is the use of evidence to inform progression. Therefore, for effective feedback that moves learners forward, teachers must have a conceptualisation of where the learner is now, what matters next for learning in the domain, and how to get the learner there (Wiliam \& Thompson, 2007). However, progression and its relationship to assessment and learning has been 'fields apart' (Pellegrino, 2017). Recognising the inexorable relationship between learning and progression, Heritage (2008) argues that,

'by its very nature learning involves progression. To assist in its emergence, teachers need to understand the pathways along which students are expected to progress. These pathways or progressions ground both instruction and assessment. Yet, despite a plethora of standards, and curricula, many teachers are unclear about how learning progresses in specific domains.' (Heritage, 2008, p. 2).

Internationally, researchers have been building understandings of learning progression across some areas of the curriculum. Pellegrino (2017) argues that research undertaken on cognition and learning has led to the emergence of highly developed descriptions of progression in particular curriculum areas (Science, Reading and Mathematics) and that 
these can form a sound basis for assessment design (e.g. Bransford, et al., 2000; Duschl et al., 2007; Kilpatrick, et al., 2001; Snow, et al., 1998). However, this remains an area where more research is required. Existing research on learning progression in some areas of the curriculum tends to make a potentially problematic assumption that learning is a linear process, and in areas such as the Humanities disciplines, it tends to be piecemeal and fine-grained rather than providing empirical evidence from broad learning across a domain from early years through the end of compulsory schooling.

\section{The CAMAU Project: Supporting the development of learning progressions}

We are a team of academics in Education who worked together on the Humanities area of the new Welsh curriculum. The three-year CAMAU Project was commissioned by Welsh Government to support the development of an understanding of progression in the drafting of the new curriculum. The project is inspired by the Integrity Model of Change (Hayward \& Spencer, 2010), originally applied to formative assessment in Scotland, but adapted here to learning progression in Wales. While there is widespread recognition that meaningful change is a complex process, this model interrogates ideas of complexity in terms of three features of integrity needed for sustainable change, namely: educational integrity, personal and professional integrity, and systematic integrity. Whilst educational integrity means a clear focus on improving learning, personal and professional integrity ensures that it aligns with 'what matters to the individual teacher, headteacher, policy maker and researcher' (Hayward \& Spencer, 2010, p.135). The model also emphasises that all participants should have a significant role in the construction of the programme, rather than being passive recipients of policy directives. Systematic integrity indicates a coherent development at all levels of the 
education system including all policies driving in the same direction and all communities sharing a same vision. This model helped us to consider complexities in terms of what decisions must be made around developing a new curriculum in order to sustain successful engagement of learning progression in the new Humanities curriculum.

This paper reflects the early work of the CAMAU project, when initial findings from our policy and literature review were shared with teachers and policy makers for their initial thoughts and reflections on the decisions that would need to be made in the development of the progression framework.

\section{Learning Progression in the Humanities}

The newly defined Humanities AoLE for the new curriculum in Wales includes the study of History, Geography, Religious Education (RE), Business and Social Studies. These subjects share common themes, concepts and discernible skills whilst also having their own discrete knowledge, concepts and skills. Successful Futures recommends that the Humanities AoLE should include aspects such as enquiry, investigation, evaluating diverse views of the world, and engaging with sustainability and social change (Donaldson, 2015).

Our review of the research on learning progressions uncovered several interesting findings on the challenges of progression in the Humanities. For instance,

'Unlike mathematics or science where the subject content intrinsically gets more complex, in the social studies, it is possible to ask the same question - for example, "What were the causes of the First World War?" or "What are our responsibilities as citizens?" - at ages 10 and 18 and expect qualitatively different answers' (Brant, Chapman \& Issacs, 2016, p. 72). 
This perspective suggests that learning progression in Humanities should allow learners to revisit skills and concepts as they progress in their learning. Rawling's (2017) report, The Welsh Curriculum Review, recommends that rather than viewing progression as 'knowing more' content, it is valuable to focus on how big ideas develop over time. For example, 'learners should know about their country and the wider world' by age 11 and by age 14 , learners 'should know about the UK in the wider world with greater depth of knowledge and understanding' (Rawling, 2017, Appendix 1.3). The implication here is progression comes both from greater depth of knowledge and from a conceptual shift in the relationship between the UK and the world, although further specification may be needed regarding how these conceptual connections are made, and to understand what is meant by greater depth of knowledge. Our review also suggested that there are multiple ways to model progression. While there was general agreement that a linear model of progression did not match the reality of learners' development in the classrooms of the teachers involved, defining an alternative model was harder.

\section{Four Tensions in the Articulation of Learning Progression in Humanities}

Through our review of the literature on progression in Humanities, a brief review of Humanities curriculum from other countries, and through our ongoing development work with the teachers, viewed through the lens of the Integrity Model of Change (Hayward \& Spencer, 2010) four tensions were identified. In order to arrive at the four tensions, we considered and discussed various debates and decisions that had to be made throughout the process of curriculum development, identified a list and categorised these into four tensions, delineated each of the tensions, and then revisited the literature and our international review (Hayward, et al., 2018) and our reflections from the work of the teachers again to further explore how research, policy, and professional evidence informs each of these tensions. The tensions were the relationship 
between disciplines; the balance between knowledge, skills and values; the differences between underlying models of progression in Humanities; and balancing the complexity of learning with practical consideration for a national curriculum.

\section{The relationship between disciplines}

The Humanities AoLE in the new curriculum of Wales encompasses geography, history, religious education, business and social studies (Donaldson, 2015). One tension when designing learning progressions within the Humanities is to determine the relationships between disciplines, for instance, should progression steps adopt progression in individual disciplines across schooling, a multidisciplinary approach or some combination? Our review revealed that countries differ in the extent to which progression of learning cover the entire Humanities area or are subject specific. Many internationally curriculum tend to move from the multidisciplinary (social studies) to disciplinary (for example, Geography) from primary to secondary school. For example, New Zealand has a single Social Studies learning area through levels 1-5, and then separate subjects of Geography, History, Sociology, and Economics through levels 6-8 (New Zealand Curriculum, 2010). However, some countries have one multidisciplinary Humanities learning area that remains through schooling. For example, in Scotland, there is one subject called Social Studies across all levels, as History and Geography are included in progression steps in an integrated fashion (Scottish Government, 2017). Interestingly, Ontario differs from above, as the curriculum increases in fragmentation at multiple levels with a single subject called Social Studies for grades 1-6; partitioned into History and Geography in grades 7-8; and then further partitioned into Economics, Geography, History, Law and Politics (within an umbrella area called Canadian and World Studies) by grade 12. The secondary level also includes Business and a separate learning area called Social Sciences and Humanities that include Equity Studies, Family 
Studies, General Social Sciences, Philosophy, and World Religions (Ontario Curriculum, 2013).

We grouped these various arrangements into three broad approaches: integrated or multidisciplinary approaches (such as Scotland) which present a more unified model; disciplinary models (such as the former Welsh curriculum) which focus on separate subjects; and interdisciplinary models (such as Ontario) which attempts to identify the connections between disciplines, without completely replacing them. The extent to which the skills described were domain specific, as opposed to more general (e.g. critical thinking) also varied across countries. Generally, teachers from primary schools were used to an integrated curriculum, which tended to lead to a focus on a more integrated model of progression. In contrast many teachers from secondary schools were used to teaching one of the constituent subjects and had a strong sense of progression in that particular discipline. Merits and challenges were identified within disciplinary and integrated learning progressions in the Humanities. For example, disciplinary learning progressions may ensure a clear direct pathway in subject specific knowledge, concepts and skills across schooling. It might be easier for teachers to monitor coverage and progression when focusing on separate subjects (Greenwood \& Kelly, 2017). However, disciplinary-only progression steps may restrict learners in making connections between related disciplines and solving real-life problems. A further tension in this area related to progression in areas that were part of other AoLEs. This was most prevalent in aspects of RE, which has had special status in the curriculum in Wales in the past, and where some teachers felt some of the core elements of their subject sat within the Health and Wellbeing AoLE. 


\section{The balance between knowledge, skills and values}

In drafting the new Curriculum for Wales, Pioneer teachers were asked to consider how learners developed their 'knowledge, skills and experiences' over time. However, the balance between each of these varies within international progression frameworks in the Humanities disciplines. In addition, several international examples also refer to values or dispositions. For example, Australia gives equal weighting to inquiry and skills and knowledge and understanding (Australian Curriculum, 2015). This is similar in British Columbia where there is reasonable balance between understanding, competencies and skills. All areas of learning, including Social Studies, are based on a 'Know-DoUnderstand' model to support a concept-based, competency-driven approach to learning (British Columbia Curriculum, 2015). In contrast, some countries place greater emphasis on inquiry and skills. In New Zealand, the Social Sciences learning area highlights the social inquiry approach which includes sub-skills such as asking questions, gathering information, exploring perspectives, and reflection and evaluation (New Zealand Curriculum, 2010). In Singapore, inquiry is used as a central pedagogy for developing Historical and Geographical understanding (Singapore Curriculum, 2015).

Similar findings were also revealed in the research literature in individual domains within the Humanities. Hopkin \& Weedon (2014) note domains of geographical knowledge (contextual, understanding, and procedural) and imply that progression in subject knowledge is key. In contrast, Wertheim \& Edelson (2013) emphasis 'key geographical practices' as essential skills that a 'good geographer' would develop (e.g. for posing geographical questions or communicating geographical information). Furthermore, one of the key themes that appeared be in several of the studies is that the understanding of progression in History has moved from being primarily based on knowledge acquisition towards being based on development of 
conceptual understanding in areas such as establishing historical significance and using sources of evidence (e.g. see Coyler, 2012; Hawkey et al., 2015). A similar trend was seen in RE, where the general approach taken was one in which learners engage at deeper levels of sophistications with more complex content (Grant \& Matemba, 2013). The previous Welsh National Curriculum, which covers 7-14, provides both a 'range' (which defines content and context) and 'skills' (for which 'best fit' attainment levels are provided). The new curriculum will be organised around 'statements of What Matters' for each AoLE, based on the work of Wintersgill (2017), with progression in learning being described in each of these statements. During professional activity similar tensions between the balance of skills, knowledge and values arose when articulating learning progressions around the five What Matters statements (WMs). Initially the teachers were conceptualising learning progression around skills and values rather than knowledge. This may reflect the system in which they currently work. For example, specific domain skills were identified from each of the WMs and progression steps were articulated around these skills. The requirement to consider the four purposes and cross-curricular responsibilities (literacy, numeracy and digital competency) when articulating learning progression steps may have influenced this decision. As a result, progression in learning in specific skills domain (e.g. mapping skills) was visible in progression steps within one WM. However, this resulted in an imbalance between knowledge and skills and teachers noted that learning progressions only focusing on skills demonstrates an inadequate articulation of learning progression in Humanities. Moreover, members of the group felt it was essential to include enquiry skills and concepts within learning progression frameworks, as enquiry skills in Humanities disciplines are different to other disciplines such as science. Teachers also identified common concepts and skills common to all of the Humanities disciplines, for example 
continuity and change. It was therefore agreed that learning progression frameworks for the new Humanities AoLE would include a balance of concepts and skills across each of the WMs.

\section{The differences between underlying models of progression in Humanities}

Another tension was what model, or combination of models, to adopt for describing learning progression in the Humanities. Whilst some models followed a linear model where learners move from one concept or skill to the next, others advocate a spiral model whereby learners are expected to revisit previous concepts/skills as they develop in order to further deepen them and potentially build new connections. Brant, Chapman, \& Isaacs' (2016) review of the Social Studies curriculum across six countries summarises four approaches to modelling progression within Social Studies, noting some of the challenges of each. One model relies on 'generic cognitive objectives' similar to Bloom's taxonomy. Two is modelling subject-specific concepts and mastery of the concepts and processes that embody disciplinary thinking (VanSledright, 2011, cited in Brant et al., 2016). Three is modelling by beginning with content similar to ‘core knowledge' approach (Cain \& Chapman, 2014, cited in Brant et al., 2016). Four is modelling the equal importance of knowledge as 'body and form', for example using models of 'historical literacy' (Lee, 2005, 2011, cited in Brant et al., 2016). The cognitive objective approach may have the disadvantage of ignoring important relationships between concepts, whilst modelling 'core knowledge' or subject-specific concepts may result in competencies that are either too specific or generic.

The research on progression in learning in Humanities tends to relate to specific subject areas such as Geography (Rawling, 2017) and History (Lee \& Shemilt, 2003), possibly reflecting the greater commonality of conceptions of the more traditional subject areas internationally, as opposed to a diverse conception of 'Humanities'. Most 
examples (such as Hawkey et al, 2015 and Rawling, 2017) use a model of progression in terms of conceptual changes that occur across time as opposed to a taxonomic approach.

International examples of learning progression in the Humanities-related subjects also offer insights into different approaches to learning progression. New Zealand's curriculum documents highlight the need to re-visit concepts in order to consolidate learning in what appears to be a spiral approach to progression (New Zealand Curriculum, 2010). Similarly, Ontario espouses a non-linear historical inquiry process whereby the order of using components of the process depends upon the student and the task (The Ontario Curriculum (2013) - Social Studies Grades 1 to 6 and History and Geography Grades 7 and 8). However, the objectives for learning in many national curricula suggest a model of progression in terms of a cognitive taxonomy. For example, Scotland's 'experience and outcomes' in Social Studies use words such as 'explore' and 'understand' in earlier steps, 'use', 'describe' and 'discuss' in middle steps, and 'evaluate' and 'explaining' at the highest step (Scottish Curriculum, 2017). In British Columbia, within the 'big idea' of 'continuity and change', at grade level 7, students are expected to be able to 'characterize different time periods in history, including periods of progress and decline, and identify key turning points that marked periods of changes' and at grade level 10 are expected to be able to 'Compare and contrast continuities and changes for different groups at particular times and places.' (British Columbia Curriculum, 2015). Although linked to the research related to this big idea, attaching learning progression to specific grades levels may suggest learning is linear and using task-based descriptions of learning may be problematic.

Similar tensions regarding the differences between underlying models of progression in Humanities was highlighted in professional activity. Teachers in Wales 
were used to linear models of progression from the existing curriculum where outcomes and levels represented attainment or achievement rather than progression in learning. As the task was to articulate progression in learning in broad terms, the practitioners in the AoLE at first modelled progression as increasing challenge in terms of 'generic cognitive objectives', similar to Bloom's taxonomy. However, members of the AoLE noted that essential aspects of content and domain specific dimensions were lost or may be so generic that they apply for all subjects in the curriculum. In other words, initial drafts did not include the necessary descriptions of changes in knowledge and skills that were expected over time. The teachers also used the model of describing progression within subject-specific concepts, for instance progression in mapping skills. However, this resulted to adding too much specificity and prescription, thus not adhering to the recommendations of Successful Futures (Donaldson, 2015). The current drafts represent an attempt by the pioneers to draw together concepts from the various subject disciplines, organised within each What Matters statement, rather than replace them with something overly generic.

\section{Balancing the complexity of learning with practical considerations for a national curriculum}

In the move from 'levels' based system to one build on progression a number of tensions between the policy, research and practice evidence has emerged. Levels of learning are statements that describe content, skills, or other outcomes that are expected to be attained at specific ages. International comparisons indicate that countries around the world that have had rapid improvement in performance (e.g., Singapore and Finland) do not use levels (OECD, 2014). Rather than assessing pupils' attainment against levels these countries have focused on specific key areas in the curriculum to promote deep, secure knowledge and understanding of these specifics. Successful 
Futures recommended a change from a previous 'levels' approach towards describing learning progression along a continuum, with progression steps describing learning at five points in this continuum which are, at least partially, linked to broad expectations at different ages. Notably, most empirical models of learning do not limit themselves to a certain number of steps, although many countries select a standard number for coherence across the curriculum. For example, New Zealand has 8 'stages' covering several years each, with a clear recognition that some pupils may attain stages earlier or later than expected (New Zealand Curriculum, 2010). On the other hand, Ontario Curriculum (2013) and British Columbia Curriculum (2015) specify learning outcomes for each grade or year level.

A related tension was the level of granularity that would be provided at a national level. In Wales, many schools had broken down the level descriptors into smaller 'sublevels' in order to aid the tracking of progress of learners. However, this practice is widely criticised in the literature (e.g. Lee \& Shemilt, 2003) and many teachers recognised that these did not always accurately describe progression as seen in pupils work and that at their worst these could have a distorting effect on learning. Hayward et al., (2018) suggest that to be effective, progression frameworks need to provide two levels of granularity - the broad level which covers the full learning journey, and a finer grained set of descriptions covering a smaller period of time. The development of this second level will require more work in the future by teachers when they write their own school-level curricula, but the evidence suggests this cannot be achieved simply by dividing the progression framework. Additional work will be required alongside the development of school level curricula to consider progression.

At various points the teachers explored describing progression in specific skills and concepts across WM steps. However, the requirement for a coherent and consistent 
approach across the whole curriculum led to this being set aside. A noticeable shift in mindset was required by teachers engaged in professional activity to think in terms of progression across the three-year range specified by Successful Futures, to be used for formative purposes. The use of the term 'achievement outcomes' was initially seen as signalling current summative practice, and was another indicator of the difficulty in shifting out of current assessment culture and practice. It is worth noting that this term has now been changed by Welsh Government.

\section{Conclusions and Implications}

In summary, it is clear that the process of conceptualising progression in learning in Humanities is complex. Our critical review of four tensions identified through the lens of the Integrity Model of Change, may help to inform current reform efforts in Wales and contribute to a better understanding more broadly of the conceptualisation of learning progression within the Humanities disciplines. The first tension reviewed was the relationship between disciplines. Future research on how disciplinary, multidisciplinary, and interdisciplinary learning progresses and what is important for improving learning across domains within Humanities is needed. Our literature review also noted a lack of evidence on progress in pupil understanding, in some specific domains within the Humanities

The second tension viewed was the balance between knowledge, skills and values. Care needs to be taken regarding this balance, for too often 'big ideas' (WM) 'are not brought together as a coherent vision for the progressive acquisition of concepts and skills' (Heritage, 2008, p.2). Without a coherent vision, the potential for teachers to have a broad overview of learning in a specific domain is restricted. This has 
implications for future professional learning and the need to consider more detailed guidance and support for teachers about learners' progression, next steps and pedagogy.

The third tension was to determine what model, or combination of models, to adopt for learning progression. In the previous Welsh curriculum, outcomes and levels were used to conceptualised attainment/achievement rather than progression in learning, yet the new curriculum notes the spiral nature of learning. The concept of progression in learning (and not progression of learning) should underpin professional development for teachers during the development and enactment of the New Curriculum for Wales 2022. Professional learning should support practitioners in planning their teaching using these new broad progression steps and to consider how an understanding of the progression models used within each area of learning can be used in the development of school-level curricula, assessment, and pedagogy. This is likely to be a long-term integrative development process, with potential for extremely useful future research.

The last tension was balancing the complexity of learning with practical considerations for a national curriculum. Promoting alignment between research, policy, and practice requires educational integrity, personal and professional integrity, and systemic integrity (Hayward \& Spencer, 2010). For decades the focus in Wales has been on levels and achievement outcomes, which has implications for changing the culture and professional habits of teachers and tensions regarding assessment for formative and summative purposes and considering what learners need to achieve to be successful in national qualifications. Furthermore, the new model in Wales requires teachers to become curriculum developers and have a clear understanding of progression. We acknowledge the difficulty of this task. When initially describing learning progression, many teachers focused on describing a particular task or the independent use of skills, 
rather than the underlying conceptual understanding. Curriculum and professional development in Wales should ensure that teachers are aware and are enabled to adopt this new culture of planning and teaching that supports future learning (rather than summarising previous learning).

Whilst there is no 'right' answer to these four identified tensions, it may be argued that for a new approach focused on learning progressions to be sustainable, the final curriculum and the way learning progression is conceptualised must have educational integrity (focus on improving learning and evidence-informed approach), personal and professional integrity (stakeholders have a significant role), and systematic integrity (coherent development of policies and communities moving in the same direction). Future research is needed to explore some of the tensions identified (e.g., which model of progression is most effective, and for what purposes) keeping in mind that the 'best' model will be the one that aligns the needs of Welsh learners and the educational, professional, and systematic integrity of Wales.

This conceptual paper makes a contribution through moving beyond the often piece-meal literature on learning progression in Humanities disciplines to provide a discussion of the big picture issues on learning progression in Humanities. We identified and delineated four tensions in terms of developing a new Humanities curriculum around learning progressions. We have critically reviewed these tensions in terms of exploring what existing evidence and professional activity in Wales suggests regarding the benefits and challenges of taking particular decisions, and in so doing so, we help raise important practical and policy implications (for other countries who may wish to incorporate learning progression in their national curriculum), and areas for future researchers to explore. 
Therefore, in order for the next stage of curriculum development to be successful, professional learning will be key. Teachers will need to understand how the new progression frameworks differ to previous models in how they conceptualise progression, and the purposes to which they will be put. The importance of an understanding of progression in the development of the school-level curriculum cannot be underestimated and our work so far suggests that time and careful engagement with not just with national policy, but also with children's work will be needed to shift thinking from the current system to that proposed in the new. Questions remain about the best ways to develop a shared understanding of progression at a finer level of detail, and to ensure that the nationally described Descriptions of Learning continue to be empirically tested, and, if necessary, revised. If teachers do not fully comprehend the goals and form of new curriculum, then their efforts to 'implement' will invariably fall back on existing practices and ways of thinking (Priestley, 2017).

\section{References}

Australian Curriculum (2015). Humanities and Social Sciences. Retrieved 5 May, 2019, from http://nzcurriculum.tki.org.nz/The-New-Zealand-Curriculum/Social$\underline{\text { sciences }}$

Black, P., \& Wiliam, D. (1998). Assessment and classroom learning. Assessment in Education, 5, 7-71.

Brant, J., Chapman, A. \& Issacs, T. (2016). International instructional systems: social studies. The Curriculum Journal, 27(1), 62-79.

Bransford, J.D., Brown, A.L., Cocking, R.R., Donovan, M.S. \& Pellegrino, J.W. (Eds.) (2000). How people learn: Brain, mind, experience, and school. Washington, DC: National Academies Press.

British Columbia Curriculum (2015). Social Studies. Retrieved May 17, 2019, from: https://curriculum.gov.bc.ca/curriculum/social-studies/7 
Coyler, J. (2012). Assessment of Historical Thinking. A report on the national meeting of The Historical Thinking Project, Toronto, January18-20, 2012. Retrieved, June 4, 2019, from, http://historybenchmarks.ca/sites/default/files/files/docs/2012Report_EN.pdf

Donaldson, G. (2015). Successful Futures: Independent Review of Curriculum and Assessment Arrangements in Wales. Cardiff: Welsh Government.

Duschl, R., Maeng, S., \& Sezen, A. (2011). Learning progressions and teaching sequences: a review and analysis. Studies in Science Education, 47, 123-182.

Estyn (2014). The Annual Report of the HM Chief Inspector of Education and Training in Wales 2013-13. Cardiff: Estyn.

Fennema, E., Carpenter, T. P., Franke, M. L., Levi, L., Jacobs, V. R., \& Empson, S. B. (1996). A longitudinal study of learning to use children's thinking in mathematics instruction. Journal for Research in Mathematics Education, 27, 403-434.

Grant, L., \& Matemba, Y.H. (2013). Problems of assessment in religious and moral education: the Scottish case. Journal of Beliefs \& Values, 34:1, 1-13.

Greenwood, J., \& Kelly, K. (2017). Implementing cycle of Assess, Plan, Do, Review: a literature review of practitioners' perspectives. British Journal of Special Education, 44(4), 395-410.

Hawkey, K., Thorne, S., Bryant, M., Rawlings, D., Kennett, R., \& Fletcher, A. (2016) Adventure in assessment. Teaching History, 161, 51-62.

Hayward, L., \& Spencer, E. (2010). The Complexities of Change: Formative Assessment in Scotland. Curriculum Journal, 21(2), 161-177.

Hayward, L., Jones, D. E., Waters, J., Maraka, M., Morrison-Love, D., Spencer, E., ... Wardle, G. (2018). CAMAU Project: Research Report (April 2018). Project Report. University of Glasgow, Glasgow. Retrieved May 20, 2019 from https://www.gla.ac.uk/media/media_587517_en.pdf

Heritage, M. (2008). Learning progressions: Supporting instruction and formative assessment. Council of Chief State School Officers (CCSSO).

HMCI Wales (2012). The Annual Report of Her Majesty's Chief Inspector of Education and Training in Wales 2011-12. Cardiff: Estyn.

Hopkin, J., \& Weedon, P. (2014). Assessing without Levels. Teaching Geography, Summer 2014, 60-63. 
Kelly, A.V. (2009). The Curriculum, Theory and Practice (6 ${ }^{\text {th }}$ ed.). London: SAGE Publications Ltd.

Kilpatrick, J., Swafford, J., \& Findall, B. (eds) (2001). Adding it up: Helping children learn mathematics. Washington: National Academy Press.

Khangura, S., Konnyu, K., Cushman, R., Grimshaw, J., \& Moher, D. (2012). Evidence Summaries: The Evolution of a Rapid Review Approach. Systematic Reviews, $1(10), 1-9$.

Lee, P., \& Shemilt, D. (2003). A scaffold not a cage: progress and progression models in history. Teaching History, 113, 13-23.

Marshall, B., \& Drummond, M.J. (2006). How teachers engage with Assessment for Learning: lessons from the classroom. Research Papers in Education, 21(2), 133-149.

New Zealand Curriculum (2010). Social Sciences. Retrieved May 7, 2019, from http://nzcurriculum.tki.org.nz/The-New-Zealand-Curriculum/Social-sciences

OECD (2010.) PISA 2009 Results: What Students Know and Can Do: Student Performance in Reading, Mathematics and Science (Volume 1), PISA. OECD: Paris.

OECD (2014). Improving Schools in Wales: An OECD Perspective. Paris: OECD.

Ontario Curriculum (2013). Humanities and Social Studies. Retrieved July 5, 2019, from http://www.edu.gov.on.ca/eng/curriculum/secondary/ssciences.html Pellegrino, J.W. (2017). The two disciplines problem - 'it's like DéJà vu all over again!' Assessment in Education: Principles, Policy and Practice, 24(3), 359368.

Priestley, M., \& Biesta, G. (2013). Introduction: The new curriculum. In M. Priestley \& G. Biesta (Eds.), Reinventing the curriculum: New trends in curriculum policy and practice. London: Bloomsbury Academic.

Priestley, M., \& Drew, V. (2016). 'Teachers as agents of curriculum change: closing the gap between purpose and practice'. Presented at European Conference for Educational Research, Dublin, 23-26 September 2016.

Priestley, M. (2017). Approaches to specifying curriculum areas of learning. Stirling: The Stirling Network for Curriculum Studies.

Rawling, E. (2017). The Welsh Curriculum Review: Developing a Curriculum Framework. Commissioned Paper by Welsh Government. 
Scottish Curriculum (2017). Aiming for Excellence. Retrieved May 20, 2019, from https://scotlandscurriculum.scot/

Singapore Curriculum (2015). Humanities. Retrieved May 22, 2019, from https://www.moe.gov.sg/education/syllabuses/humanities/

Snow, C.E., Burns, M., \& Griffin, M. (Eds.) (1998). Preventing reading difficulties in young children. Washington, DC: National Academics Press.

Welsh Government (2008). Skills Framework for 3 to 19-year-olds in Wales. Cardiff: Welsh Government.

Wertheim, J., \& Edelson, D. (2013). A Road Map for Improving Geography Assessment. The Geography Teacher, 10(1), 15-21.

Wiliam, D., \& Thompson, M. (2007). Integrating assessment with learning: what will it take to make it work? In: The Future of Assessment: Shaping Teaching and Learning. Mahwah, NJ: Lawrence Erlbaum Associates, 53-82.

Wintersgill, B. (2017). Big Ideas for Religious Education. Exeter: University of Exeter. 
